\title{
EFICIENCIA Y COMPETENCIA EN EL MERCADO DE combustibles de la República Dominicana
}

\author{
Por Yulisa Benzan a , Osmel Brito, \\ Alejandro RodríGuez ${ }^{\mathrm{b}}$ y Harold VÁSQUez ${ }^{\mathrm{c}}$ \\ Recibido: febrero de 2019 • Aceptado: abril de 2019
}

Cómo citar: Benzan, Y., Brito, O., Rodríguez, A., \& Vásquez, H. (2019). Eficiencia y competencia en el mercado de combustibles de la República Dominicana. Ciencia, Economía y Negocios, 3(2), 61-106.

Doi: https://doi.org/10.22206/ceyn.2019.v3i2.pp61-106

\section{Resumen}

Este documento analiza algunas de las normativas que rigen el mercado de combustibles dominicano con el objetivo de proponer mejoras que incrementen la eficiencia y la competencia. Partiendo de un análisis descriptivo y econométrico para estimar la importancia del mercado de los combustibles en la economía dominicana, el trabajo se concentra en analizar aspectos de la legislación relacionados con la fijación de precios, de márgenes de intermediación y de costos de entrada dentro del sector, para luego realizar una serie de recomendaciones orientadas a reducir los costos de operación e incrementar el dinamismo del mercado. El trabajo muestra que los costos de entrada, al igual que el establecimiento de precios a través de la fórmula de Precio de Paridad de Importación (PPI), son mecanismos ineficientes que dislocan el uso de recursos y elevan los costos del uso de combustibles energéticos para las empresas y para el consumidor final. El mercado de combustibles dominicano cuenta con un número importante de actores que permiten una mayor competencia dentro de este mercado.

Palabras clave: combustibles; competencia; Precio Paridad de Importación.

Códigos JEL: D01, D41, D43.

a yulisabenzan@gmail.com

baerod098@gmail.com

c Vásquez, H. Instituto Tecnológico de Santo Domingo (INTEC). Dirección: Escuela de Economía y Negocios. Av. Los Próceres \#49, Los Jardines del Norte 10602, Santo Domingo, República Dominicana. T: +1 (829)341-5979. (e-mail: harold.vasquez@intec.edu.do). Benzan, Y., Brito, O. \& Rodríguez, A. DatAnalítica. Dirección: Gustavo Mejía Ricart 120, Edificio Las Anas, Local 203. Piantini, Santo Domingo, República Dominicana. T: +1(809)378-1094. (e-mail: osmel.b@datanalitica.com). 


\title{
EFFICIENCY AND COMPETITION IN THE DOMINICAN REPUBLIC'S FUEL MARKET
}

\author{
Por Yulisa Benzan a , Osmel Brito, \\ Alejandro RodríGuez ${ }^{\mathrm{b}}$ y Harold VÁsqueZ ${ }^{\mathrm{c}}$
}

Received: february, 2019 • Approved: april, 2019

\begin{abstract}
This document analyzes the regulations that govern the Dominican fuel market and propose improvements that increase market efficiency and competition. We combined a political economy and applied econometric focus to analyze the regulatory framework related to pricing, intermediation margins, and entry costs within the sector, and we propose several recommendations aimed at reducing operating costs and increasing market dynamism. We conclude that the industry entrance costs and the determination of prices through the Import Parity Price (PPI) formula are inefficient mechanisms that dislocate the use of resources and raise the costs of using energy fuels for consumers and businesses.
\end{abstract}

Keywords: fuel price; competition; Price Import Parity; oligopoly.

JEL codes: D01, D41, D43.

a yulisabenzan@gmail.com

baerod098@gmail.com

c Vásquez, H. Instituto Tecnológico de Santo Domingo (INTEC). Dirección: Escuela de Economía y Negocios. Av. Los Próceres \#49, Los Jardines del Norte 10602, Santo Domingo, República Dominicana. T: +1 (829)341-5979. (e-mail: harold.vasquez@intec.edu.do). Benzan, Y., Brito, O. \& Rodríguez, A. DatAnalítica. Dirección: Gustavo Mejía Ricart 120, Edificio Las Anas, Local 203. Piantini, Santo Domingo, República Dominicana. T: +1(809)378-1094. (e-mail: osmel.b@datanalitica.com). 


\section{Introducción}

Los hidrocarburos constituyen la principal fuente de energía a nivel mundial. En República Dominicana, las importaciones de combustibles han estado en aumento consistentemente durante las últimas dos décadas, conforme incrementa el nivel de renta de los hogares $-\mathrm{y}$ con esto su demanda energética- surgen nuevas industrias y crece el parque vehicular nacional. En el año 2005, el volumen importado de hidrocarburos -i.e., gas natural, petróleo y derivadosfue de 46.5 millones de barriles (MMb); este volumen alcanzó 60.3 $\mathrm{MMb}$ en el año 2017, indicando un aumento interanual de un $2.9 \%$ para todo el período ${ }^{1}$.

Con el aumento de la demanda, también ha incrementado el número de actores y proveedores que participan en el mercado de combustibles dominicano. Por ejemplo, la Refinería Dominicana de Petróleo (REFIDOMSA) -que por mucho tiempo fue el principal importador y proveedor local de combustibles- en el año 2017 importó solo el $37.8 \%$ del total de petróleo y derivados, compartiendo el mercado con otros actores privados como las empresas ESSO, Vienergy, Coastal Dominicana y AES Dominicana, por citar algunos casos.

Aunado a lo antes planteado, la República Dominicana tiene un parque vehicular con más de 4 millones de vehículos -aunque gran parte de estos son motocicletas- y unas 800 estaciones de dispendio de combustibles líquidos esparcidas en toda la geografía nacional. Más aún, una variedad de naciones en distintas regiones -incluidas Colombia, Trinidad y Tobago, Nigeria y Países Bajos- abastecen el mercado local. Sin embargo, a pesar de la diversidad de oferentes

\footnotetext{
1 Utilizamos el término combustibles o hidrocarburos para referirnos al petróleo, a los derivados del petróleo y al gas natural. Específicamente, en este ensayo el término combustible incluye petróleo crudo, gasolina, gasoil, gas licuado de petróleo (GLP), gas natural, fuel-oil, gasolina de aviación, avtur y otros combustibles. Cuando usemos el término de petróleo y derivados, nos referiremos a todos los combustibles mencionados anteriormente, exceptuando al gas natural. También, en adelante, las medidas de volumen estarán indicadas en barriles -incluyendo el gas natural, para el cual utilizamos una conversión- y el precio de los combustibles estará en dólares por barril (USD/barril), a menos que se indique lo contrario. También, el término millones de barriles será indicado por MMb.
} 
y demandantes, el mercado de combustibles dominicano permanece estrictamente regulado, situación que crea ineficiencias en la asignación de recursos, limita la competencia y deriva en mayores precios para los consumidores. El objetivo de este trabajo es analizar esta problemática y realizar algunas recomendaciones de política económica orientadas a incrementar el bienestar social.

El marco jurídico que regula el mercado de combustibles dominicano está esencialmente contenido en la Ley de Hidrocarburos 112-00 y su Reglamento de Aplicación, dictado mediante el Decreto 307-01. Específicamente, la normativa establece un Precio de Paridad de Importación (PPI) que debe ser revisado periódicamente por el Ministerio de Industria, Comercio y Mipymes (MICM) con el objetivo de fijar el precio final de venta que deben aplicar los detallistas de combustibles. También, la normativa establece el precio máximo al que deben vender las terminales de importación de combustibles, fija los márgenes de comercialización por la distribución, el transporte y la venta al detalle de combustibles, además de los pagos relacionados con los permisos y las licencias que deben adquirir importadores, almacenistas, transportistas y vendedores al detalle para operar en el mercado. Con una vigencia de casi dos décadas, este marco jurídico no está ajustado a la realidad de la economía dominicana, la cual corresponde a una economía más dinámica, abierta y competitiva que la existente previa a la ley, lo que introduce un conjunto de costos regulatorios que -más allá de los impuestos- hace que los precios de los combustibles sean más elevados que el nivel que correspondería a una economía de mercado competitivo y produce externalidades que reducen el bienestar social.

Los costos regulatorios del marco jurídico del mercado de combustibles pueden clasificarse en tres categorías: (1) costos de entrada, (2) costos de asignación de recursos y (3) costos políticos. Los costos de entrada están relacionados con los pagos de permisos, licencias y renovaciones que permiten operar a las empresas, como importadores, almacenistas, transportistas o detallistas de combustibles. Estos costos son de índole observable, alcanzando sumas millonarias por el pago de licencias y permisos, como no observables, 
cuando son medidos en términos del costo de oportunidad del capital que enfrentan las empresas para esperar que dichas licencias sean concedidas.

Los costos de asignación de recursos se refieren a aquellos costos que enfrenta el supervisor para determinar los precios de venta de combustibles y los márgenes de operación de las empresas; incluyen los costos que afrontan las empresas al no poder asignar de manera eficiente sus recursos de capital y trabajo (e.g., niveles de inversión fuera del óptimo) y que surgen como resultado de la inexistencia del mecanismo de precios de mercado.

Finalmente, el costo político está relacionado con el costo de popularidad en que incurre el gobierno cada vez que debe efectuar, a través del MICM, un cambio en el precio de los combustibles que no es percibido como "justo" por la sociedad. El alcance de este estudio no incluye una estimación de dichos costos, puesto que para eso se requeriría hacer un levantamiento costoso de información, sino que se centra en la identificación de estos. Con la aplicación de políticas adecuadas, en este trabajo argumentamos que estos costos pueden ser minimizados produciendo una mejora en el bienestar de la sociedad.

El documento está estructurado de la forma siguiente. En la sección II presentamos un análisis sobre el impacto del mercado de combustibles en la economía dominicana, y luego, en la sección III, contextualizamos este mercado a nivel regional dentro de los países miembros del SICA. En la sección IV se presentan las trabas regulatorias que existen en el mercado de combustibles dominicano. Debido a su importancia como herramienta regulatoria, explicamos la fórmula de establecimiento de combustibles y el mecanismo de Precios de Paridad de Importación, en la sección V. En la sección VI se presentan las críticas y recomendaciones de política, mientras que en la sección VII se finaliza con las conclusiones del trabajo. 


\section{Mercado de combustibles y su impacto en la economía dominicana}

\section{A. Importación de hidrocarburos}

Para las economías en vía de desarrollo, los hidrocarburos son una fuente indispensable de energía, debido al alto costo de oportunidad que aún representa la generación de energía renovable. En República Dominicana, los combustibles representan un componente importante dentro de la balanza comercial; de allí que las fluctuaciones en los precios y/o en la producción mundial tengan repercusiones significativas en los desequilibrios macroeconómicos y en la actividad productiva. Por eso, presentamos a continuación algunos elementos que caracterizan la demanda importada de hidrocarburos y su impacto -en términos de Producto Interno Bruto (PIB)- en la balanza comercial.

Los combustibles son la principal materia prima de importación de la República Dominicana. En el año 2005, la factura de combustible nacional ascendió a USD 2,450 millones de dólares, equivalente al $33 \%$ del valor total de las importaciones. Desde entonces, la factura de combustibles promedia unos USD 3,300 millones anuales, alcanzando un máximo de USD 4,790 millones en el año 2012 -o el $27 \%$ del total de importaciones-, momento en que el barril de petróleo cotizó la cifra más alta de las últimas dos décadas, alcanzando 140 USD/barril (dólares por barril). Recientemente, con el desarrollo de la tecnología de fracturación de rocas para la extracción de petróleo y gas de esquisto, la oferta mundial de combustibles ha incrementado de forma importante, resultando en una caída dramática de los precios; como es de esperar, la economía dominicana se ha beneficiado de este escenario, reduciendo su factura de combustibles hasta USD 2,846 millones -apenas un $16.1 \%$ de las importaciones- en el año $2017^{2}$.

\footnotetext{
${ }^{2} \mathrm{Al}$ momento de realizar este trabajo, los datos de la balanza de pago dominicana y de importación de combustibles solo estaban disponibles hasta septiembre de 2018. Decidimos presentar el análisis hasta el año 2017, último año con datos completos, por fines comparativos.
} 
Del total de combustibles importados, el petróleo y sus derivados representan el componente más importante de la factura de combustibles, totalizando USD 2,592 millones -o 46.8 millones de barriles (MMb)- en el año 2017. En cambio, el gas natural representó un total importado de USD 255 millones (13.5 MMb) en ese año. Entre los productos de petróleo y derivados importados se destacan el petróleo crudo, gasoil, gasolina, Avtur y demás combustibles de aviación, fuel-oil y lubricantes de motor.

En el año 2017, las importaciones dominicanas de petróleo crudo alcanzaron USD 406 millones, representando el 2.3\% del total de importaciones. La importación de petróleo crudo se ha reducido significativamente en la última década y media, desde un total de 15.2 $\mathrm{MMb}$ en 2005 , hasta 7.3 MMb anuales en el año 2017. Es importante indicar que la reducción de la demanda de petróleo crudo no constituye una reducción de la demanda total del grupo petróleo y derivados, debido al aumento en la importación de otros productos como la gasolina y el gasoil para vehículos de motor.

La demanda de gasolina y gasoil, el rubro de importación más importante entre los productos derivados del petróleo, alcanzó 14.8 MMb (o USD 991 millones de dólares) en el año 2017. Esta demanda es inelástica, ya que fue muy estable durante el período 2005-2017, promediando unos $13.5 \mathrm{MMb}$, con una desviación estándar de 1.8 $\mathrm{MMb}$, a pesar de las significativas fluctuaciones en los precios internacionales del petróleo. La figura 1 muestra la evolución de la importación de los principales rubros de combustibles, en millones de barriles (eje derecho), y el precio promedio de importación, en dólares por barril (eje izquierdo).

A diferencia de la demanda de gasolina y gasoil, la demanda de importación de fuel-oil, específicamente el fuel-oil \#2 y fuel-oil \#6 para la generación eléctrica, presenta una alta variabilidad de corto plazo, debido a la constante entrada y salida de plantas generadoras de energía y a la sustitución de combustibles que realizan algunas

Para septiembre de 2018, la factura de combustibles dominicana ascendió a USD 2,824 millones, cifra equivalente al $18.9 \%$ del total de importaciones. 
de estas plantas con sistema dual de producción, lo cual le permite sustituir entre combustibles según varían los precios internacionales. No obstante, observando un amplio horizonte de tiempo, la demanda de fuel-oil no varió significativamente durante el período 2005-2017, ya que apenas incrementó en 3.1 MMb, equivalente a un crecimiento promedio de 3.5\% anualizado. En el año 2017, la economía dominicana importó 9.2 $\mathrm{MMb}$ de fuel-oil, equivalentes a USD 450 millones. Por otro lado, las importaciones de Avtur (o combustible de aviación) se han duplicado en los últimos años al incrementar desde USD 100 millones, en 2005, hasta unos USD 205 millones, en 2017. Este crecimiento es cónsono con el dinamismo observado en el sector de servicios aeronáuticos y de turismo, ya que el Avtur es utilizado mayormente como producto de reexportación.

En general, las importaciones de petróleo y derivados mantienen una tendencia moderada creciente, consonante con el crecimiento de la economía dominicana. En el año 2005, la República Dominicana importó un total de $43.8 \mathrm{MMb}$, cifra que se elevó hasta $50.1 \mathrm{MMb}$ en 2016. A pesar del crecimiento, el volumen total de combustibles importados es más estable a lo largo del tiempo, debido mayormente a los cambios que ocurren en la matriz energética, lo cual trae como resultado que combustibles derivados del petróleo sean reemplazados en mayor volumen por el gas natural. Así, en el año 2016 las importaciones de combustible alcanzan un nivel récord de 60 millones de barriles, a causa de la significativa reducción del precio promedio del barril importado, el cual disminuyó hasta USD 43/barril en $2017^{3}$.

\footnotetext{
${ }^{3}$ El precio promedio del barril de combustible importado en República Dominicana es calculado como la relación entre el valor total de importación (en dólares USD) y la cantidad de barriles importados. Este indicador es una medida más exacta, en comparación con los precios de referencia de los mercados internacionales, de lo que cuesta en promedio a la economía dominicana importar un barril de combustible.
} 
Figura 1. Precio y Volumen de importación promedios de los combustibles en República Dominicana. Período 2005-2017.

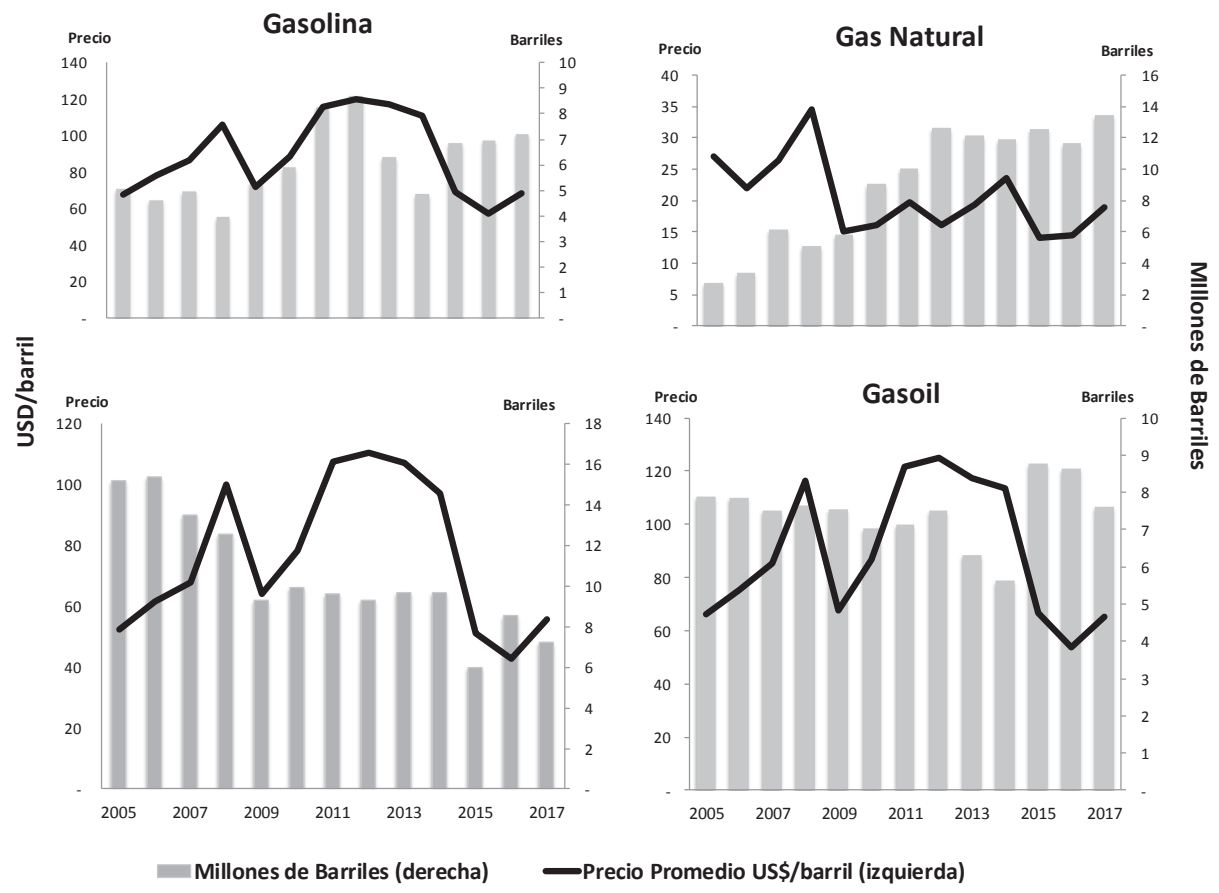

Notas. Precio promedio en USD/barril y volumen en millones de barriles ( $\mathrm{mm} / \mathrm{b})$.

En la última década, las importaciones de gas natural han crecido a un ritmo promedio de un $14 \%$ anual, lo que ha resultado en un aumento del volumen importado, de $2.7 \mathrm{MMb}$ en 2005, hasta 13.5 $\mathrm{MMb}$ en 2017. El incremento en la demanda de gas natural se debe al cambio en la matriz energética dominicana, ya que más del $70 \%$ de las importaciones son utilizadas en la generación de energía y el restante en vehículos de transporte. En el año 2017, las importaciones de gas natural totalizaron unos USD 254 millones. Esperamos que este patrón de sustitución de combustibles continúe en el futuro, según siga avanzando el cambio de la matriz energética, y que tome un rol más importante la generación de energía con otras fuentes, como el carbón, la energía eólica, solar, entre otras fuentes de energías renovables. 
B. Procedencia de las importaciones, importadores y mercado de vehículos

Como consecuencia de eventos internos y externos, la procedencia de las importaciones dominicanas de combustibles ha variado en las últimas dos décadas. Por el lado interno, el uso de gas natural en la matriz energética dominicana ha favorecido las importaciones desde países que en períodos anteriores no eran contemplados, como es el caso de Trinidad y Tobago. Del lado externo, factores geopolíticos, como la crisis de Venezuela, han aumentado la participación de las importaciones desde otras naciones como Colombia. Al mismo tiempo, los avances tecnológicos en la extracción de petróleo y gas natural hicieron que Estados Unidos (EE. UU.) se convierta en un exportador neto de combustibles, con precios mucho más atractivos, lo que ha incrementado las importaciones desde esa nación.

En el año 2000, las importaciones dominicanas de combustibles provenían mayormente de Venezuela (con un $50 \%$ del total de importaciones), de México (con el 20\% del total) y, en menor medida, de Estados Unidos (con un 4\% del total). Para el año 2005, debido a conflictos en la producción, las importaciones de combustibles desde Venezuela se reducen hasta un 26\% del total (unos $12 \mathrm{MMb}$ importados), favoreciendo las importaciones desde otros países, como Colombia y Trinidad y Tobago. En el año 2015, Estados Unidos se convierte en el principal proveedor de combustibles del mercado dominicano, con un $35 \%$ del total (unos $20.4 \mathrm{MMb}$ ), mientras que se moderaron las importaciones desde Venezuela y México, cubriendo solo el $10 \%$ y $5 \%$, respectivamente, del total de combustibles importados. 
Figura 2. Importaciones de gasolina en República Dominicana POR PAís DE PROCEDENCIA PERÍOdo 2005-2018

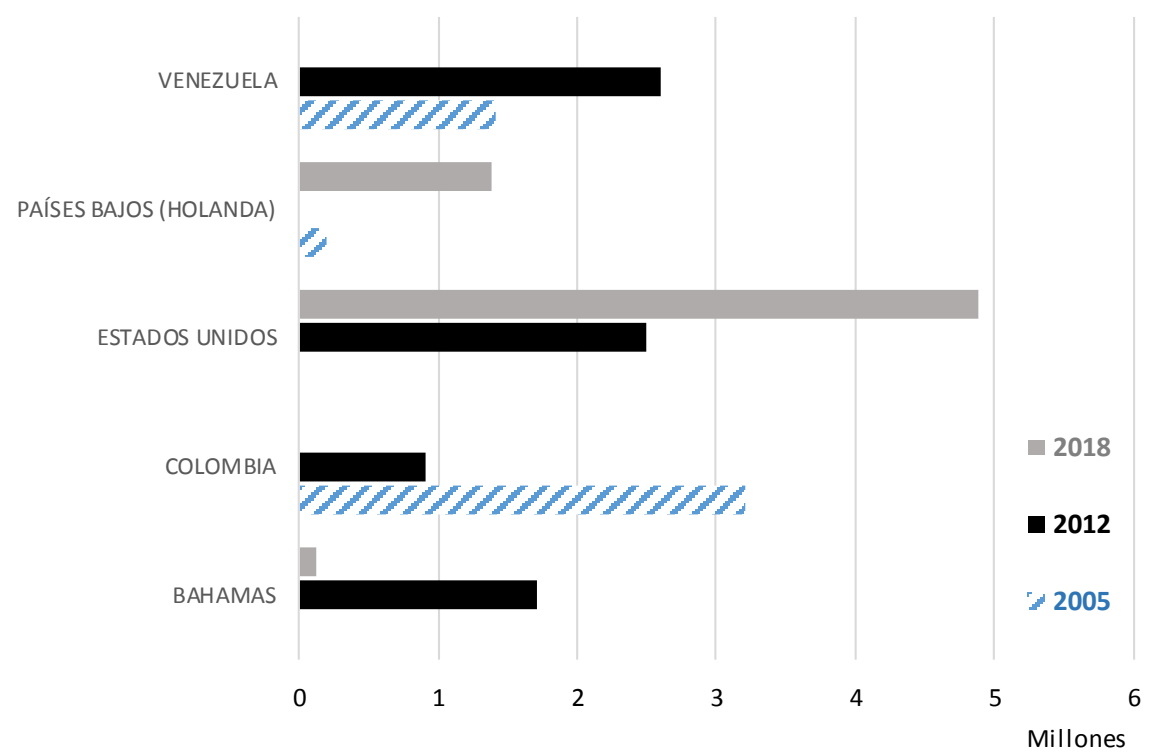

Figura 2. Importaciones de gasolina en República Dominicana por país de procedencia. Período 2005-2018. Notas. Volumen en millones de unidades de barriles $(\mathrm{mm} / \mathrm{b})$.

Con respecto al sector importador, el principal importador de combustibles es la Refinería Dominicana de Petróleo (en adelante, REFIDOMSA), empresa de capital mixto, con el 51\% de capital accionario del gobierno dominicano y el resto del gobierno venezolano. En el año 2016, REFIDOMSA importó el 37.8\% del total de petróleo y derivados. Las empresas Falconbridge y REFIDOMSA son las únicas en el negocio de refinación de petróleo crudo, teniendo esta última la mayor participación. REFIDOMSA provee casi el 50\% de todo el combustible utilizado para el transporte a nivel nacional, seguida por las empresas ESSO y Vienergy, ambas de capital totalmente privado, las cuales importan gran parte del combustible restante para vehículos. La empresa Coastal Dominicana está enfocada en el mercado de Gas Licuado de Petróleo (GLP) y AES Dominicana es la única empresa importadora de gas natural, el cual es utilizado en más del $80 \%$ de los 
casos para la generación de energía eléctrica y el porcentaje restante como combustible vehicular.

Figura 3. Importaciones de petróleo crudo en República Dominicana Por país de PRocedencia Período 2005-2018.

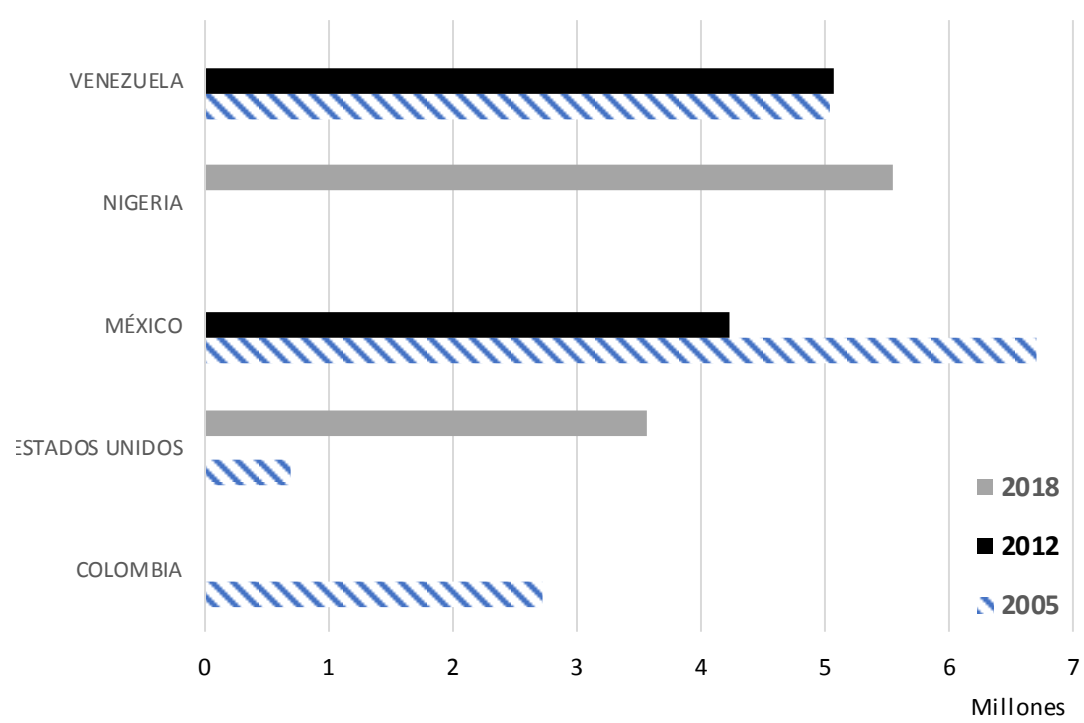

Notas. Volumen en millones de unidades de barriles $(\mathrm{mm} / \mathrm{b})$.

El incremento del parque vehicular dominicano es uno de los factores de mayor incidencia en el aumento de las importaciones de combustibles. Por ejemplo, en el año 2017 el parque vehicular nacional contaba con unos 4 millones de vehículos, más del doble de la cantidad de vehículos que circulaban en el año 2005. Esta cifra incluye motocicletas, automóviles, autobuses y todo tipo de vehículo usado para la carga o el transporte público y privado. En la actualidad, Santo Domingo y el Distrito Nacional tienen la mayor concentración de vehículos, con el $40.1 \%$ del total del parque vehicular nacional.

A pesar del aumento del parque vehicular, el consumo de gasolina y gasoil se ha mantenido estable desde el año 2006, cerca de los 300 millones de galones anuales, lo cual está relacionado con el mayor uso de vehículos que operan con combustibles diésel, GLP y gas 
natural. En 2005, el combustible de mayor consumo fue el gasoil, con 395 millones de galones. Sin embargo, en el año 2006, el combustible GLP supera la demanda de gasoil, reportando un consumo de 350 millones de galones, mientras que el consumo de gasoil disminuyó a 340 millones de galones. Desde entonces, el GLP es el combustible de mayor consumo en República Dominicana, con un consumo actual de 475 millones de galones, en 2017.

Figura 4. Distribución del parque Vehicular por tipo de transporte en República Dominicana. Período 2004-2017.

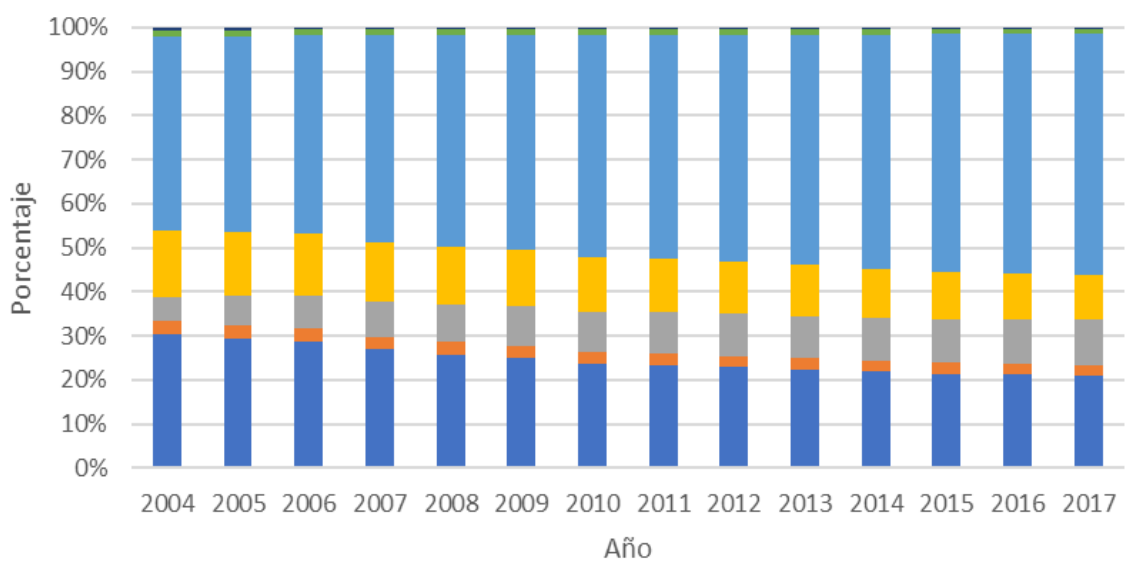

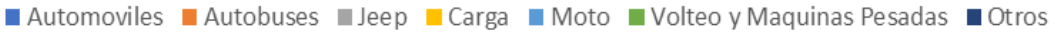

Notas. Distribución como porcentaje del total de vehículos.

\section{Impacto macroeconómico de los combustibles en la República Dominicana}

En el Anexo A de este documento presentamos en detalle un análisis de regresión donde estimamos el impacto de los combustibles en la balanza de pagos dominicana. Los resultados de las estimaciones indican que el aumento de un $1 \%$ en el precio promedio del petróleo importado incrementa el déficit de la Cuenta Corriente de la balanza de pagos en el $0.128 \%$ del Producto Interno Bruto (PIB), o el equivalente a un aumento de USD 104 millones en el déficit de la Cuenta 
Corriente. Además, en términos de la Cuenta Corriente de equilibrio (i.e., el nivel de Cuenta Corriente que corresponde a los fundamentos de la economía dominicana), las estimaciones indican que por ser un país importador neto de petróleo, la economía dominicana enfrenta un costo equivalente al $1.35 \%$ del PIB. Es decir, más de $40 \%$ del déficit de Cuenta Corriente correspondiente a los fundamentos de la economía (estimado en un 3.3\% del PIB) se debe a que República Dominicana es un país importador neto de combustibles.

\section{Mercado de combustibles a nivel regional: países miembros del SICA}

Con fines de colocar dentro del contexto regional el mercado de combustibles dominicano, hacemos una comparación del mercado local con el mercado de los países miembros del Sistema de Integración Centroamericano (SICA): Belice, Costa Rica, El Salvador, Guatemala, Honduras, Nicaragua y Panamá. Algunas de las variables consideradas en este análisis incluyen el precio interno, el consumo y la procedencia de las importaciones de hidrocarburos de cada uno de estos países. Las informaciones presentadas en esta sección fueron elaboradas a partir de las estadísticas recopiladas en el informe Centroamérica y República Dominicana: estadísticas de hidrocarburos, publicado cada año por la Comisión Económica para América Latina y el Caribe (en adelante, CEPAL), donde fueron consultados específicamente los informes correspondientes al período 2013-2017.

\section{A. Demanda de combustibles en los países del SICA: relación de comercio importación de combustibles a exportaciones totales}

Para medir la importancia de las importaciones de combustibles relativas al flujo comercial de cada país, utilizamos la relación de importación de combustibles sobre exportaciones totales. Así, en el año 2000, la República de Nicaragua importó en hidrocarburos USD 25.2 por cada USD 100 dólares de exportaciones totales (o el 25.2\%), 
presentando la mayor relación de combustibles importados sobre exportaciones de la región. Mientras, República Dominicana, Guatemala y El Salvador presentaron una relación de combustibles importados a exportaciones de $15.8 \%, 15.6 \%$ y $14.2 \%$, respectivamente. Esta relación de intercambio aumentó de forma importante en el período 2005-2008 en todos los países de la región, debido al aumento generalizado en el precio internacional del petróleo, el cual superó los USD 130/barril. Como resultado, el gobierno venezolano, en ese entonces presidido por Hugo Chávez, propuso la firma del Acuerdo Petrocaribe, el 29 de junio del año 2005. Particularmente, la negociación dominicana contempló el pago de la deuda adquirida por concepto de financiación de combustibles con la exportación de productos agrícolas, lo cual, en hechos prácticos, no fue materializado.

La crisis económica de la Gran Recesión de 2009 revirtió esta situación, pues uno de los resultados fue la caída de los precios internacionales del petróleo hasta USD 50/barril, mejorando así los términos de intercambio de la mayoría de los países miembros del SICA. En ese sentido, entre los países más beneficiados están: Nicaragua, con una reducción de 10.5 puntos porcentuales en la relación de combustibles importados a exportaciones; República Dominicana, con una reducción de 8.8 puntos porcentuales; y El Salvador, con una reducción de 7 puntos porcentuales.

En el año 2010, la República Dominicana ocupó el primer lugar de la región en destinar una mayor proporción de las ganancias percibidas por concepto de exportaciones totales a las importaciones de hidrocarburos, con un 27.8\%; seguida de El Salvador, con el $27.2 \%$; Honduras, con un $23.3 \%$ y Nicaragua, con el $22.1 \%$; estas relaciones se han mantenido estables desde entonces.

\section{B. Importación de hidrocarburos}

En el año 2013, las importaciones de hidrocarburos en los países del SICA ascendieron 169.1 MMb, donde 142.6 MMb (84.3\%) correspondieron a derivados del petróleo, $14.4 \mathrm{MMb}(8.5 \%)$ a petróleo crudo y 12.1 MMb (7.2\%) a GLP. Durante ese año, las importaciones 
desde Trinidad y Tobago representaron el 9.7\% de la factura del total de importaciones de los países de la región, que ascendió a USD 17,400 millones, en su mayor parte GLP adquirido por la República Dominicana.

En 2013, el volumen de importación de productos refinados aumentó un $2.4 \%$, pero las importaciones de crudo y la factura de hidrocarburos (petrolera y gas natural) disminuyeron un $15.1 \%$ y un $2.3 \%$ con respecto al año anterior, esto como resultado del comportamiento de los precios del mercado petrolero internacional.

En 2015, las importaciones de hidrocarburos de los países del SICA experimentaron un crecimiento de un $12 \%$ (192.2 MMb) respecto al 2013, correspondiendo el $88.1 \%$ a derivados del petróleo, el $5.8 \%$ a petróleo crudo y el $6.1 \%$ a gas natural. Las importaciones desde Trinidad y Tobago experimentaron una reducción de un $6.4 \%$ de la factura del total de importaciones de los países de la región, que ascendió a USD 10,900 millones.

El volumen de las importaciones de productos refinados en 2015 registró un aumento de un $12.3 \%$, las importaciones de crudo disminuyeron en un $24.4 \%$ y la factura petrolera mostró una drástica reducción de un $34.4 \%$ con respecto al año anterior, como consecuencia del desplome de los precios en el mercado petrolero internacional.

\section{Producción de combustibles derivados del petróleo}

Según los datos de CEPAL, la producción de los derivados de crudo en las refinerías de los países miembros del SICA está en descenso. Por ejemplo, comparando el nivel de producción del año 2010, el proceso de refinación de petróleo a nivel regional descendió en un $10.5 \%$, en 2013, y en un $27.3 \%$, en 2015. La salida del mercado de diversas plantas de refinación, como la refinería Recope de Costa Rica, en 2011, y la refinería Rasa de El Salvador, en 2012, explican esta situación.

Hay que destacar que, de los 8 países del SICA, solo en Nicaragua y República Dominicana operan plantas de refinación: REFIDOMSA y ALBANISA. Al año 2015, estas plantas abastecieron el 43\% y el 9\% de la demanda interna de hidrocarburos, en sus respectivas naciones. 


\section{Distribución en el mercado minorista}

Según las estadísticas presentadas por la CEPAL en lo que concierne a la distribución minorista, las estaciones de servicio registradas para el período 2012-2017 fueron los siguientes:

Tabla 1. Número de estaciones de Combustibles líquidos en Centroamérica y República Dominicana

\begin{tabular}{cccccccc}
\hline & $\begin{array}{c}\text { Costa } \\
\text { Rica }\end{array}$ & $\begin{array}{c}\text { EI } \\
\text { Salvador }\end{array}$ & Guatemala & Honduras & Nicaragua & Panamá & $\begin{array}{c}\text { República } \\
\text { Dominicana }\end{array}$ \\
\hline 2012 & 344 & 392 & 1256 & 395 & 290 & 404 & 656 \\
2013 & 340 & 399 & 1140 & 392 & 296 & 374 & 656 \\
2014 & 350 & 402 & 1342 & 392 & 296 & 421 & 651 \\
2015 & 364 & 430 & 1342 & 392 & 302 & 448 & 823 \\
2016 & 359 & 441 & 1976 & 405 & 305 & 488 & 823 \\
2017 & 376 & 443 & 1806 & 405 & 309 & 498 & 823 \\
\hline
\end{tabular}

Fuente: Comisión Económica para América Latina (CEPAL).

En 2013, el total de estaciones registradas en los países miembros del SICA descendió un 3.7\%, con relación al año anterior, debido al cierre de dos refinerías en la región. Sin embargo, en 2014 y 2015 el número de estaciones creció en un $6.0 \%$ y un $6.4 \%$, respectivamente.

En 2016, Guatemala y Panamá presentaron un crecimiento acelerado en el número de estaciones, de un $32.1 \%$ y un $8.2 \%$, respectivamente, con relación al año anterior. Mientras, en República Dominicana el número de estaciones de combustibles líquidos ha permanecido estancado desde el año 2015, en un total de 823 estaciones, lo cual podría estar motivado por las condiciones y las trabas que coexisten en el mercado dominicano de combustibles y que serán explicadas más adelante.

E. Precios de distribución en los mercados internos

En los países miembros del SICA, los precios internos de los combustibles son establecidos de formas diferentes. Es importante 
destacar que la República Dominicana tiene el mayor precio de los combustibles derivados del petróleo cuando es comparada con los países de Centroamérica. Por ejemplo, en 2005 el precio promedio anual de la gasolina en el mercado dominicano fue de 3.36 dólares por galón (USD/gl) americano (3.78 litros), el más alto de los países de la región. Mientras, Panamá presentó los precios internos de gasolina más bajos, con $2.51 \mathrm{USD} / \mathrm{gl}$. Cabe señalar que el mercado de combustibles de Panamá está totalmente desregularizado, es decir, los precios no son fijados por las autoridades gubernamentales. En general, como muestra la figura 5, la República Dominicana ha sido el país con el mayor nivel de precios de combustibles (a excepción del año 2008) dentro del grupo de países que conforman el SICA, durante el período 2005-2015 (ver figura 5).

Para el año 2018, el nivel de precios de los combustibles entre países miembros del SICA se había elevado. Por ejemplo, en República Dominicana la gasolina regular costaba $4.81 \mathrm{USD} / \mathrm{gl}$; mientras, el precio de este combustible fue $4.05 \mathrm{USD} / \mathrm{gl}$, en Costa Rica; 3.58 USD/gl, en Honduras; 3.65 USD/gl, en Nicaragua; 3.26 USD/gl, en El Salvador; 3.19 USD/gl, en Guatemala; y 2.91 USD/gl, en Panamá. $\mathrm{Si}$ bien es cierto que los impuestos directos e indirectos pueden explicar gran parte del porqué son más elevados los precios de los combustibles en República Dominicana con relación a Centroamérica (algunos analistas sugieren que los impuestos explican un 70\% de las diferencias de precios), otro elemento importante son los márgenes de intermediación, los cuales son fijados por el MICM, entre otros costos que podrían derivase del mercado interno y la regulación. 
Figura 5. Evolución del PRecio InTERno de LA Gasolina REgUlar en LOS PAíses MIEMBros DEL SICA.PERÍOdo 2005-2015.

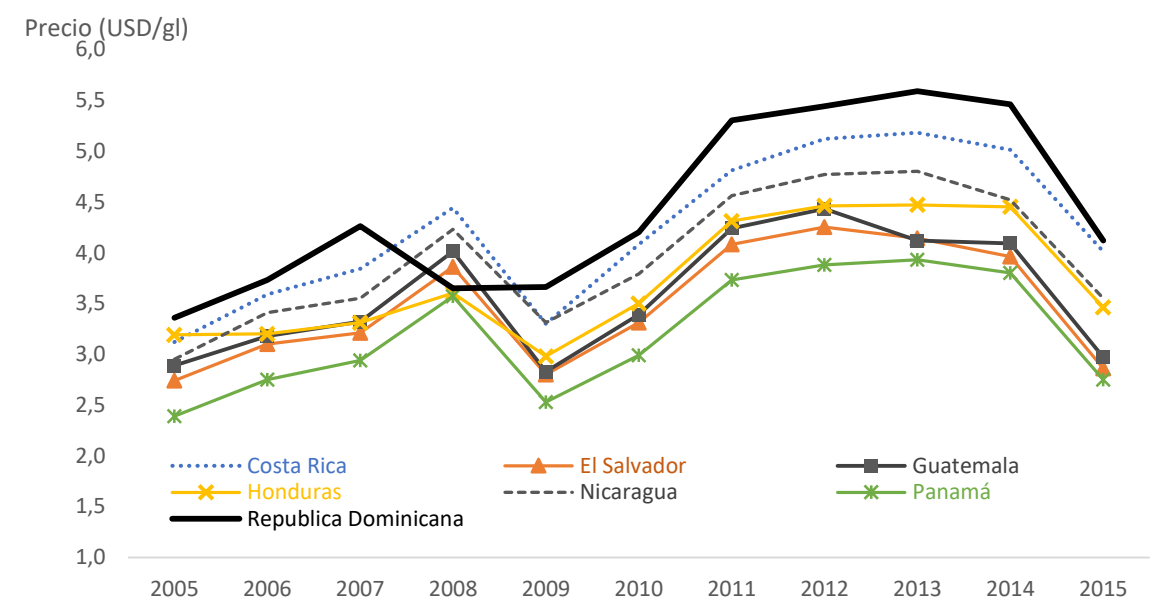

Notas. Precio en dólares por galón (USD/gl) e incluyen impuestos locales.

\section{Trabas existentes en el mercado local de hidrocarburos}

El Estado dominicano regula la importación y la comercialización de combustibles a través de la Ley 112-00 sobre Hidrocarburos y su Reglamento de Aplicación, dictado mediante el Decreto 307-01 en el año 2001. Este sistema regulatorio impone ciertas barreras de entrada al mercado de los combustibles, dificultando la competencia y elevando los costos de operación de las empresas, traduciéndose en mayores precios hacia los consumidores. Las barreras de entrada se presentan de diversas formas, incluyendo costo de solicitud, pago de licencias de importación, licencias de distribución como mayoristas de combustibles, licencia de venta al detalle, licencia para transporte y renovaciones. Además, otros costos que incluye la normativa están relacionados con el costo de oportunidad del capital, los cuales no son fácilmente observables y podrían ser sustanciales. Estos costos están relacionados con el tiempo de respuesta sobre el otorgamiento 
de dichas licencias, las cuales se pueden extender hasta los 90 días de forma reglamentaria. La tabla 2 muestra algunos de los permisos y las licencias requeridos, junto al tiempo mínimo de respuesta indicado en los reglamentos ${ }^{4}$.

Tabla 2. Permisos necesarios para operar

EN EL MERCADO DE COMBUSTIBLES

\begin{tabular}{lccc}
\hline Tipo de permiso & $\begin{array}{c}\text { Costo de } \\
\text { solicitud }\end{array}$ & $\begin{array}{c}\text { Costo de } \\
\text { licencia }\end{array}$ & $\begin{array}{c}\text { Tiempo de } \\
\text { respuesta }\end{array}$ \\
\hline $\begin{array}{l}\text { Licencia de productos derivados del pe- } \\
\text { tróleo por unidad móvil }\end{array}$ & $30,000.00$ & $40,000.00$ & 30 \\
$\begin{array}{l}\text { Renovar la licencia otorgada por el } \\
\text { MICM para el transporte de combusti- }\end{array}$ & $5,000.00$ & $10,000.00$ & 30 \\
$\begin{array}{l}\text { bles por unidad móvil. } \\
\text { Licencia de importador de derivados del } \\
\text { petróleo, incluyendo GLP, con terminal } \\
\text { de almacenamiento propia. }\end{array}$ & $55,000.00$ & $100,000.00$ & 90 \\
$\begin{array}{l}\text { Renovación de la licencia para la im- } \\
\text { portación de derivados del petróleo con } \\
\text { terminal de almacenamiento }\end{array}$ & $110,000.00$ & $1,000,000.00$ & 90 \\
$\begin{array}{l}\text { Licencia para la importación de deriva- } \\
\text { dos del petróleo sin terminal de almace- } \\
\text { namiento }\end{array}$ & $25,000.00$ & $500,000.00$ & 30 \\
$\begin{array}{l}\text { Licencia para la importación de deriva- } \\
\text { dos del petróleo sin terminal de almace- } \\
\text { namiento }\end{array}$ & $10,000.00$ & $200,000.00$ & 30 \\
$\begin{array}{l}\text { Licencia para la operación de terminal } \\
\text { de almacenamiento de derivados del pe- } \\
\text { tróleo para la venta o el consumo propio. }\end{array}$ & $55,000.00$ & & \\
$\begin{array}{l}\text { Licencia para reexportación de deriva- } \\
\text { dos del petróleo }\end{array}$ & $25,000.00$ & $300,000.00$ & 45 \\
$\begin{array}{l}\text { Licencia para la distribución mayorista } \\
\text { de combustibles líquidos }\end{array}$ & $25,000.00$ & $500,000.00$ & 30 \\
$\begin{array}{l}\text { Renovación de la licencia para la dis- } \\
\text { tribución mayorista de combustibles } \\
\text { líquidos }\end{array}$ & $10,000.00$ & $200,000.00$ & 30 \\
\hline
\end{tabular}

Fuente: Ministerio de Industria, Comercio y MiPymes.

\footnotetext{
${ }^{4}$ Acorde a lo establecido en los reglamentos sobre el mercado de combustibles, el tiempo de respuesta a las solicitudes de licencias y permisos va desde los 30 hasta los 90 días. Sin embargo, el tiempo efectivo en que en la práctica podría tardar una empresa en tener los permisos necesarios para empezar podría ser muy distinto.
} 
A pesar de los costos de entrada, el mercado de combustibles dominicano está compuesto por 34 empresas distribuidoras mayoristas de combustibles líquidos, 94 distribuidoras de Gas Licuado de Petróleo (GLP) y unas 2,668 estaciones de expendio de combustibles en todo el territorio nacional. A la vez, las empresas distribuidoras están distribuidas actualmente entre 1,304 estaciones de expendio de combustibles líquidos y 1,364 estaciones de Gas Licuado de Petróleo (GLP). No obstante, a pesar del gran número de estaciones de expendio que conforman el sector, estas no operan bajo un sistema de competencias de mercado, sino a través de un mecanismo de precios regulados determinados en base a una fórmula de cálculo, que se explica en la siguiente sección.

\section{Fórmula del combustible en República Dominicana}

La fórmula denominada Precio de Paridad de Importación, en adelante PPI, se utiliza para la fijación oficial de los precios de venta de los combustibles -excepto el precio del Gas Licuado de Petróleo que tiene un precio de venta igual para todas las terminales-mediante resoluciones dictadas semanalmente por el Ministerio de Industria y Comercio. El marco legal de la PPI está establecido en la Ley 112-00, del año 2000, sobre Hidrocarburos y su Reglamento de Aplicación, dictado mediante el Decreto 307-01 de fecha 2 de marzo de 2001, con la intención de incentivar la competencia entre las importadoras en referencia al precio y la calidad del servicio que ofrecen. Sin embargo, no es evidente que las regulaciones establecidas en el marco jurídico cumplan este cometido.

En esencia, el principio de paridad de importación radica en que los precios de venta para las terminales de combustibles son establecidos en función de lo que le hubiese costado al Estado dominicano, bajo el supuesto de que todos los productos han sido importados bajo la PPI y los componentes de costos agregados.

Es importante señalar que hay otros factores que el Ministerio de Industria y Comercio incluye dentro del cálculo del precio de los combustibles a causa de leyes referentes al valor final al consumidor, 
cuyo componente básico son los impuestos fijos establecidos por la Ley 112-00 sobre Hidrocarburos y el denominado "Ad Valorem", contemplado en la Ley 495-06 de Rectificación Tributaria. Además, se toman en cuenta algunos márgenes establecidos por el Ministerio de Industria y Comercio en beneficio y protección de los transportistas de combustibles, distribuidores y detallistas. Los precios de venta de los combustibles a nivel local son publicados y anunciados semanalmente por los distintos periódicos de circulación nacional y medios de comunicación a nivel general.

El establecimiento de los precios de venta de los combustibles a través de esta fórmula tiene como objetivo fundamental reflejar de manera actualizada los precios de los combustibles en el mercado internacional a la tasa de cambio suministrada por el Banco Central de la República Dominicana. El Ministerio de Industria y Comercio establece el precio de venta ex-terminal a las compañías distribuidoras sobre los productos con precios regulados o determinados por la terminal de acuerdo con la PPI, los requerimientos que exige INDOCAL y los acuerdos con terceros autorizados por el Estado dominicano para operaciones no contempladas en la PPI; además de la compra de derivados del petróleo realizada por las terminales en el mercado internacional de suplidores y/o volúmenes que no están bajo contrato.

La fórmula que determina el Precio de Paridad de Importación de los combustibles se puede representar de la siguiente forma:

$$
\text { (1) } \mathrm{PPI}=\mathrm{FOB}+\mathrm{FT}+\mathrm{SM}+\mathrm{CB}+\mathrm{OC}+\mathrm{CMT}+\mathrm{GLA}
$$

Donde: PPI es el precio de paridad de importación; FOB es Free On Board o su equivalente en español Libre a bordo, puerto de carga convenido; FT es pago por flete; SM es seguro marítimo; CB son los costos bancarios; OC son otros Costos; CMT es el cargo por manejo de terminal; y finalmente, GAL es el gasto de administración de la Ley de Hidrocarburos, el cual percibe el regulador. Para ilustrar un ejemplo de cómo es utilizada esta fórmula en la práctica, procedemos a explicar detalladamente dichos componentes. 
- Precio de Paridad de Importación (PPI). Es resultado de la sumatoria de todos los costos y cargos asociados aceptados por el Estado dominicano en la fórmula de paridad de importación y comprende un ajuste por calidad en cuanto al octanaje, contenido de azufre, número de cetano del diésel, viscosidad del petróleo industrial, etc. El octanaje hace referencia a la capacidad antidetonante del combustible a descargar cuando se comprime dentro del cilindro de un motor. Mientras más alto es el nivel de octanaje del combustible, mayor calidad o pureza tiene. El azufre es un componente natural del petróleo crudo y, en efecto, se encuentra presente tanto en la gasolina como en el diésel. La reducción en el contenido de azufre en los combustibles disminuye las emisiones de estos compuestos contaminantes. En República Dominicana existe una serie de especificaciones definidas por la American Society for Testing Materials (ASTM) que deben cumplir todos los combustibles producidos por REFIDOMSA, con la intención de minimizar las emisiones de estos componentes.

Como se había mencionado, el precio oficial de venta de los combustibles resulta de la suma del PPI, los impuestos, los márgenes de distribución, los márgenes de detalle y la comisión de transporte que ha establecido el Ministerio de Industria y Comercio.

- Valor Free on Board (FOB). Constituye el componente principal del costo de los combustibles líquidos derivados del petróleo y los biocombustibles. Se podría definir de manera llana como el costo de embarque de los combustibles puestos en el puerto, por lo que al valor FOB se deben sumar los costos de los seguros y de los fletes. El costo FOB se expresa en dólares por galón (USD/gl), ajustado por la tasa de cambio del peso dominicano, según lo estipula la Ley de Hidrocarburos.

Según establece la Ley Tributaria de los Hidrocarburos No. 11200, en su capítulo VI, el costo FOB para los hidrocarburos se basa 
en el precio de publicación de todos los martes del combustible de referencia Platt's USGC Waterbone de la semana anterior, simulando de esta forma el entorno competitivo del mercado de la USGC en el país; se calcula utilizando los precios de los productos pertenecientes a dicho mercado a excepción del GLP, los cuales se publican en forma continua a través de fuentes de información públicas y oficiales. Este elemento es importante pues, como mostraremos más adelante, el precio del Platt's USGC no es el mejor indicador para reflejar los costos de importación del petróleo crudo o sus derivados, importados en República Dominicana.

En el caso del costo FOB para el GLP se toma como base el precio "Mont Belvieu" NON TET, que hace referencia a que el precio designado solo se aplica al producto comercializado en las instalaciones de Mont Belvieu Caverns, que es una subsidiaria de Enterprise Products Partners, del martes de la semana anterior del mercado spot para el Golfo de México y la costa Este de los Estados Unidos (Houston, Texas), Venezuela y Trinidad y Tobago. El precio FOB del GLP resulta del promedio de los precios mínimos y máximos cotizados para propano y butano o de la mezcla de ambos en la proporción de $70 \%$ de propano y $30 \%$ de butano del martes de la semana anterior.

- Costo de Flete (FT). Se puede denominar el precio de flete que se debe pagar por el desplazamiento marítimo de los hidrocarburos o costo de transportación en el que se debe incurrir. El precio de flete estándar para los productos blancos (excepto el GLP) desde el Golfo de los Estados Unidos al área del Caribe se obtiene de la publicación de la tarifa Worldscale hacia río Haina o cualquier otro puerto del país, multiplicado por el escalador de mercado de buques publicado en Platt's para buques de 30,000 toneladas métricas.

Los productos blancos son productos del extremo alto del proceso de destilación como la gasolina. El precio de flete estándar para los productos negros (incluyendo el Fuel-Oil) en ruta del Caribe 
a la Costa Atlántica se obtiene igualmente de la publicación de la tarifa Worldscale hacia río Haina o cualquier otro puerto del país, multiplicado por el escalador de mercado de buques publicado en Platt's para buques de 70,000 toneladas métricas.

En el caso del precio de flete estándar para el GLP, la tarifa a considerar será el promedio simple de las cotizaciones de todas las terminales obtenidas para el total de los embarques anuales de cada una de las terminales, en base a cargamento estándar entre 3,000 a 6,000 toneladas métricas, con una periodicidad de 36 a 52 embarques anuales por un período de 12 meses para el valor de las compras planeadas por cada terminal para el año, tomando en cuenta los cuatro principales puntos de importación del Golfo de México, incluyendo la costa Este de los Estados Unidos, así como Venezuela y Trinidad y Tobago.

En este sentido, hay que considerar que una vez que es establecido el parámetro referente para la tarifa de flete, las diferentes terminales tienen libertad para elegir las compañías de transporte marítimo a ser contratadas.

- Seguros Marítimos (SM). Tienen como objetivo principal indemnizar los daños producidos por los riesgos propios de la navegación marítima de los buques o las mercancías. En este caso, el seguro marítimo que se le aplica anualmente a los embarques es el valor promedio de las cotizaciones realizadas entre octubre y noviembre de cada año, por producto, para un período de 12 meses, que cada una de las terminales realiza entre las diez principales compañías de seguros del país, además de tener en cuenta los distintos puntos de carga del Golfo de México, incluyendo la costa Este de los Estados Unidos, Venezuela y Trinidad y Tobago. Las cotizaciones se realizan individualmente, tanto para los productos negros como para los productos blancos.

- Comisiones Bancarias (CB). Son cargos que los bancos cobran como compensación por sus servicios sobre la base del total 
de barriles a ser importados cada año, tales como: comisión de cambio de divisas, costo de apertura de cartas de crédito y transferencias bancarias realizadas a través de los bancos comerciales del país.

Las comisiones bancarias que se toman en cuenta para la fijación del parámetro dentro de la fórmula incluyen los gastos de transferencia y la apertura de cartas de crédito aplicables al embarque, al igual que el seguro marítimo; comprenden el valor promedio de las cotizaciones realizadas entre octubre y noviembre de cada año, por producto, para un período de 12 meses, entre los cinco bancos comerciales del país.

- Otros Costos (OC). Hacen referencia a aquellos en los que se pueda incluir que no corresponden a una ninguna de las otras categorías. Como parámetro de referencia se toma el promedio ponderado de las cotizaciones sometidas anualmente por las terminales para el valor total de los embarques, indicando las bases sobre las cuales han sido incluidos y determinados.

- Gasto de Administración de Ley (GAL). Es un costo local que se agrega en la fórmula de paridad con la intención de que el Ministerio de Industria y Comercio reciba una comisión liquidada semanalmente por las empresas importadoras para cubrir los costos relativos a la fiscalización y la supervisión de las recaudaciones del impuesto en que incurra el Ministerio de Hacienda.

- Cargo por Manejo de Terminal (CMT). Cargo establecido por el Ministerio de Industria y Comercio en conjunto con el Ministerio de Hacienda, con previa solicitud documentada por parte de las terminales, incluyendo un análisis de ingresos, costos y beneficios de cada una. 


\section{Críticas y recomendaciones}

\section{A. Sobre el Precio de Paridad de Importación (PPI)}

La normativa que regula el mercado de los combustibles contiene una serie de requerimientos que limitan la competencia e impiden que el mercado funcione de forma eficiente, causando distorsiones en el establecimiento de precios y la distribución de los recursos económicos. Las distorsiones que discutiremos a continuación están relacionadas con: (i) los componentes que conforman el Precio de Paridad de Importación; (ii) los costos explícitos e implícitos derivados del requerimiento de licencias de operación; y (iii) el costo político de los ajustes de precios. A continuación, examinemos el caso de la PPI por sus componentes.

Primero, el valor FOB del petróleo y sus derivados, el cual constituye la base principal para la determinación de los costos, es determinado a partir del precio de la canasta de petróleo Platts, que es el precio primario de referencia que se utiliza para las entregas físicas de petróleo crudo desde el Golfo de Oriente Medio hacia las refinerías asiáticas. El Platts es uno de los cuatro principales tipos de petróleo de referencia internacional, junto al West Texas Intermediate (WTI), el Brent y el Mars. Sin embargo, el Platts no es el combustible que mejor refleja el tipo de combustible importado en la República Dominicana y, por tanto, su precio no guarda la mayor correlación con el precio promedio de los combustibles importados en nuestro mercado. 
Tabla 3. Modelos de Regresión estimados Para Petróleo y DERIVADOS DEL MERCADO DOMINICANO

\begin{tabular}{|c|c|c|c|c|c|c|}
\hline \multirow{2}{*}{$\begin{array}{l}\text { Variables e indica- } \\
\text { dores }\end{array}$} & \multicolumn{6}{|c|}{ Coeficientes de los modelos estimados } \\
\hline & 1 & 2 & 3 & 4 & 5 & 6 \\
\hline WTI & 0.984 & & & 0.481 & & 0.333 \\
\hline Brent & & 0.915 & & 0.468 & 1.299 & 0.333 \\
\hline Platts Dubai & & & 0.948 & & -0.398 & 0.333 \\
\hline $\mathrm{R}^{2}$-ajustado & 0.960 & 0.961 & 0.946 & 0.963 & 0.961 & FMI \\
\hline Correlación & 0.973 & 0.981 & 0.985 & 0.979 & 0.979 & 0.982 \\
\hline RMSE & 43.850 & 38.239 & 42.352 & 39.645 & 38.257 & 41.316 \\
\hline Diferencia Máxima & 8.280 & 8.060 & 10.831 & 7.894 & 7.204 & 13.519 \\
\hline Diferencia Mínima & $(15.164)$ & $(12.073)$ & (11.905) & $(12.812)$ & (12.177) & $(9.322)$ \\
\hline $\begin{array}{l}\text { Diferencia Máxima } \\
(\%)\end{array}$ & 0.113 & 0.087 & 0.117 & 0.099 & 0.127 & 0.142 \\
\hline $\begin{array}{l}\text { Diferencia Mínima } \\
(\%)\end{array}$ & $(0.253)$ & $(0.177)$ & $(0.224)$ & $(0.214)$ & $(0.187)$ & $(0.156)$ \\
\hline $\begin{array}{l}\text { Correlación de } \\
\text { dif-logarítmica }\end{array}$ & 0.590 & 0.563 & 0.609 & 0.586 & 0.524 & 0.604 \\
\hline
\end{tabular}

Notas: estimado con datos mensuales para el período enero 2013-diciembre 2018. La variable dependiente es el precio promedio de importación del petróleo y derivados en la República Dominicana. Todos los coeficientes son significativos al $5 \%$ de nivel de confianza. Los colores indican que mientras más cercano al verde, la correlación es mayor; al amarillo, la correlación es intermedia; y, al rojo, la correlación es baja o nula.

La tabla 3 muestra las estimaciones de un modelo de regresión que relaciona el precio promedio de importación de los combustibles de petróleo y sus derivados (variable dependiente) con el precio de algunos de los principales combustibles de referencia internacional. Las columnas de la 1 a la 5 muestran los resultados para diferentes regresiones con los coeficientes estimados para cada variable relacionada al WTI, Brent, Platts o combinaciones de dichos combustibles (panel de arriba). En el panel de abajo (en colores) la tabla presenta diferentes medidas de correlación entre el valor del pronóstico ajustado de la regresión y el precio promedio de importación. Los colores indican diferentes niveles de intensidad en la correlación, con el verde indicando una alta correlación, el amarillo 
indicando una correlación media y el rojo sugiriendo una correlación baja entre las variables consideradas.

Las estimaciones indican que el precio del combustible de referencia Platts presenta el menor valor ajustado, medido por el $\mathrm{R}^{2}$ de la regresión. En ese sentido, los combustibles WTI y Brent presentan un mayor valor de ajuste; es decir, los combustibles WTI y Brent reflejan con mayor precisión, en comparación con el Platts, el valor de los combustibles importados en República Dominicana. Más aún, al considerar los indicadores de correlación del segundo panel, la estimación de la columna 4 indica que el mejor indicador de referencia que podría utilizarse en una fórmula que refleje el precio de los combustibles locales resulta de tomar un promedio ponderado entre los precios de referencia WTI y Brent. En este caso, el valor ajustado del modelo es $\mathrm{R}^{2}=.96$ y este modelo presenta los mejores indicadores de correlación.

En general, el precio del Platts no es el mejor indicador que se puede utilizar dentro de la fórmula del PPI para fijar el precio de los combustibles en el mercado. Una mejor estimación resulta de tomar el promedio ponderado de los combustibles WTI y Brent (ver figura 6). Sin embargo, la relación estimada no necesariamente es estable en el tiempo y puede cambiar según las condiciones del mercado internacional de los combustibles afecten el lugar de procedencia de los combustibles importados, la matriz energética local, entre otros elementos importantes, lo cual indica que utilizar precios de referencia internacionales para estimar el precio de los combustibles locales es un proceso que estará compuesto de errores.

Utilizar un precio de combustible de referencia equivocado para el cálculo del PPI presenta varios problemas. Primero, si el precio establecido acorde al valor de cotización del Platts está por debajo del valor efectivo de los combustibles importados en ese momento, el Gobierno dominicano presenta una pérdida y debe subsidiar la diferencia. De igual modo, si el valor cotizado del Platts queda por encima, entonces el Gobierno incrementa los costos de los combustibles más allá de lo que dictan las condiciones del mercado, perjudicando la actividad económica nacional, elevando los costos 
de energía y transporte más allá de los que dictan las condiciones de mercado. En ambos casos, con la pérdida fiscal o los altos precios, la actividad económica se ve afectada y se incurre en costos innecesarios que son asumidos por los ciudadanos.

Estas ineficiencias pueden ser costosas si consideramos que el precio FOB utilizado en la PPI es ajustado semanalmente, con una semana de rezago, no reflejando así las condiciones actuales del mercado. Con un precio libre de importación, que cada importador ajusta a las refinadoras y distribuidoras de combustibles, los agentes económicos pueden ajustar su demanda a las condiciones del mercado sin incurrir en pérdidas para el Gobierno. Más aún, el mecanismo de precios es capaz de señalizar cuando el combustible es escaso y, por ende, hacer que los consumidores racionen su uso cuando es necesario. Esto resulta en mayores beneficios sociales producto de liberar recursos para otras actividades económicas, un uso más racional de vehículos de transporte que, a su vez, produce menos tráfico y contaminación, entre otros beneficios que podríamos citar.

$\mathrm{Al}$ igual que el valor FOB del Platts utilizado como referencia, existen otros elementos en la fórmula del cálculo del PPI que inducen a serias ineficiencias. Por ejemplo, el costo de flete (CT) está relacionado con la cotización del Platts. También, los costos de flete, los seguros marítimos (SM) y las comisiones bancarias (CB) son valores estimados a partir de valores promedios de cotizaciones de años anteriores de los proveedores, i.e., instituciones financieras y aseguradoras. Al igual que el valor FOB del Platts, estos precios no reflejan condiciones actuales y limitan la competencia en este mercado. Específicamente, al fijar los precios en base a cotizaciones de años anteriores, la normativa impide que las instituciones financieras y las aseguradoras compitan de forma más agresiva, creando nuevas opciones de pólizas ajustadas a las condiciones de sus clientes y del mercado, que sin duda varían con las fluctuaciones del mercado de combustible internacional. Más aún, si las condiciones del mercado internacional cambian y los importadores deben cambiar de proveedores, empresas de cargo o instituciones financieras, estos ajustes -que podrían resultar en reducciones de costos a los consumidores- no serían incorporados en los precios. 
Figura 6. Precio de la factura petrolera dominicana y Valor estimado en base a eCUACión 4 del modelo de Regresión Período 2013-2018.

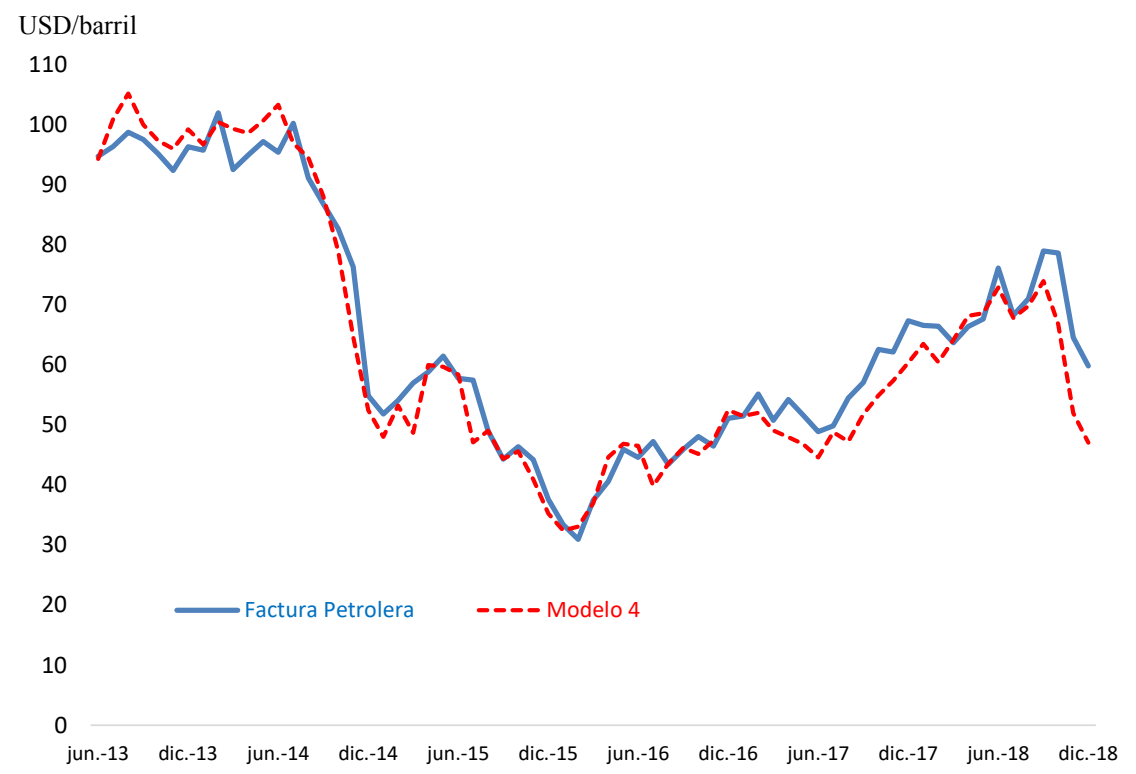

Notas. Precio en dólares por barril (USD/barril). Para ver coeficientes estimados, revisar la Tabla 3 del documento.

La fórmula de cálculo de la PPI incluye un componente de Otros Costos (OC) no relacionados a los costos de importación de los combustibles y que resultan de estimaciones basadas en las cotizaciones anuales sometidas por las terminales. Al utilizar un valor único, la entidad reguladora asume que los costos son similares entre las empresas de embarque y las terminales de combustibles. Más aún, los costos en que incurren cada una de estas empresas, no relacionados al valor de combustibles, no son observables por el ente regulador. En ese sentido, no es claro que el regulador esté capturando los costos referenciados, ya que esta medida está basada en promedios de cotizaciones, no en reportes de costos efectivos, e incluso podría estar sobreestimando el Precio de Paridad de Importación. En un mercado de libre competencia, el precio establecido en las terminales reflejaría el componente relacionado a otros costos de cada una de las empresas 
que operan. Al mismo tiempo, dado que dichos precios serían diferenciados y observables, es posible determinar cuáles empresas operan de forma más eficiente e incurren en menores costos, lo que forzaría a las empresas ineficientes a readecuar sus operaciones o a salir del mercado.

Finalmente, la fórmula de paridad incluye un cargo por gasto de administración legal (GAL) con la finalidad de supervisar el proceso de recaudación de impuestos, el cual constituye de forma indirecta un gravamen adicional para cubrir los costos de cumplimiento. No obstante, este cargo no sería necesario si el sector operara bajo las condiciones del mercado al igual que otros sectores de la economía, ya que la Dirección General de Impuestos Internos ha mostrado tener los recursos necesarios, tanto de personal como en materia de recursos tecnológicos, para realizar una adecuada supervisión. En la actualidad, la DGII supervisa de forma adecuada industrias mucho más complejas que importan, producen y/o comercializan miles de productos diferenciados (que incluyen gravámenes distintos), sin mostrar mayores inconvenientes para la recaudación de los impuestos establecidos en el código tributario.

\section{B. Costos de entrada y operación en el mercado}

En la tabla 2, sección IV, presentamos algunos de los costos por concepto de permisos y licencias en que deben incurrir las empresas que participan en la importación, el almacenamiento, el transporte y la venta al detalle de combustibles en el mercado dominicano. Cabe señalar que una misma empresa puede incurrir en participar en diversas actividades dentro de este mercado, lo cual resulta en el pago de sumas millonarias en términos de licencias de operación. Los costos mostrados en la tabla referida solo corresponden a costos explícitos y no muestra costos implícitos o costos de oportunidad del capital que asumen las empresas por el tiempo de respuesta del otorgamiento de estas licencias.

Para precisar la importancia de los costos del capital, veamos un ejemplo. Suponiendo que un empresario desea invertir DOP 50 
millones en el negocio de distribución mayorista de combustibles líquidos, el costo regulatorio observable corresponde a los pagos de DOP 25,000 para la solicitud del permiso y DOP 500,000 para la obtención de la licencia, totalizando DOP 525,000. Sin embargo, el tiempo mínimo de duración para este trámite estipulado en los reglamentos es de 90 días. Asumiendo una tasa libre de riesgo de inversión en bonos gubernamentales entre un $9 \%$ y un $12 \%$, el costo de oportunidad de dicha inversión está entre DOP 1.09 millones y DOP 1.44 millones, para el plazo de 90 días. Incluso, si el tiempo de tramitar las solicitudes y los permisos correspondientes se extiende hasta 180 días, el costo de oportunidad podría alcanzar entre DOP 2.2 millones y DOP 2.9 millones. En términos generales, el costo total observable y no observable de los permisos y las licencias para operar estarían entre un mínimo de DOP 1.6 millones y un máximo de DOP 3.4 millones. Estos costos podrían ser mayores si existen inconvenientes en el proceso que retarden el otorgamiento de las licencias.

En general, los cargos por solicitud y renovación de licencias pueden constituir un costo de entrada significativo para las empresas, limitando así la inversión, el dinamismo y la competencia en el mercado de los combustibles dominicanos. República Dominicana no produce ni contiene reservas de combustibles y necesita de la abundancia de estos para su desarrollo económico. Por eso, la política del Gobierno debe estar orientada a fomentar la participación y la entrada de empresas en este mercado a los fines de incrementar la abundancia de este recurso, lo cual tendrá un impacto tanto en la calidad como en los precios.

\section{Márgenes de intermediación}

El Reglamento de la Ley de Hidrocarburos 112-00, dictado mediante Decreto 307-01, al igual que el Reglamento del Mercado Nacional de Gas Licuado de Petróleo, Ley 250, facultan al Ministerio de Industria, Comercio y Mipymes (MICM) para establecer los márgenes de distribución y detalles que aplican a los diferentes agentes que participan 
en el mercado de combustibles dominicano. Pero, el establecimiento de márgenes de intermediación mediante resoluciones emitidas por la entidad reguladora presenta una serie de problemas desde el punto de vista económico, los cuales discutiremos a continuación.

Primero, el MICM no puede observar los costos de operación de cada uno de los actores dentro del mercado, por lo que resulta imposible que pueda establecer un margen que corresponda al nivel de eficiencia de cada empresa. Más aún, el establecimiento de un margen único para las empresas en un sector (e.g., venta de combustible al detalle, o transporte) implica que estas enfrentan los mismos costos operativos y de capital. Por ejemplo, al fijar los márgenes de las empresas detallistas de combustibles, el MICM asume que todas las estaciones enfrentan los mismos costos y las mismas restricciones económicas sin importar elementos como su localización; acceso al suministro de energía eléctrica, agua, seguridad pública y otros servicios; costos de mano de obra; costos de insumos y suministros; etc. Además, este supuesto implica que las empresas tienen los mismos niveles de eficiencia o capacidad de acceder a capital y recursos tecnológicos, supuestos que resultan incongruentes en una economía de mercado.

Segundo, el MICM reduce el incentivo de que las empresas sean más eficientes cuando fija los márgenes de intermediación. Dado que fijar los márgenes resulta en una garantía de recursos para las empresas que operan, estas no tienen incentivos para mejorar sus procesos. Esto reduce el nivel de inversión de las empresas, tanto en capital físico como humano, mediante la adquisición de maquinarias y equipos más modernos o la inversión en capacitación de sus empleados, al tiempo que mantiene operando empresas ineficientes y que de otro modo quedarían fuera del mercado dada su estructura de costos.

Tercero, la teoría económica establece que mientras un sector se aproxima hacia la competencia perfecta, los márgenes de beneficios de las empresas se van reduciendo, lo cual resulta en un menor precio del producto y un mayor beneficio para el consumidor. Al fijar los márgenes de intermediación, el MICM desincentiva la operatividad de este mecanismo de mercado, evitando así que los consumidores obtengan precios más bajos, correspondientes a un mercado competitivo. 
Cuarto, dado que el MICM no puede observar las funciones de costos y niveles de eficiencia de cada uno de los actores que operan, sería difícil pensar que el margen establecido sea el correspondiente al margen óptimo que resulta de un mercado competitivo. En ese sentido, establecer un margen diferente tiene serias consecuencias en la asignación de los recursos económicos. Por ejemplo, si el margen establecido por el MICM se coloca por encima de ese nivel óptimo, esto incentivará un exceso de entrada de empresas en el sector, lo cual reduce la cantidad de recursos de capital disponibles para otras inversiones productivas en la economía. Al mismo tiempo, para las empresas que ya operan en el sector, un margen superior al nivel de competencia se reflejará en un exceso de inversión en activos improductivos que se observará en edificaciones, grandes terrenos $\mathrm{y}$ otros activos que no justificarían su inversión o adquisición en un sistema de mercados competitivos. Por otro lado, si el margen establecido queda por debajo del óptimo, esto resultaría en la menor entrada de empresas y el desincentivo de inversión.

\section{Costo político de la regulación}

La regulación del mercado tiene serios costos políticos para el Gobierno, por diversas razones. En primer lugar, dado que los ajustes de precios son emitidos mediante resoluciones del MICM, la ciudadanía no necesariamente los relaciona con eventos que ocurren en el mercado. Además, si los ajustes ocurren para compensar aumentos de costos ocurridos anteriormente, por ejemplo, la PPI toma en cuenta precios de referencia del combustible Platt's que cotizaron en la semana anterior, la ciudadanía podría entender que estos aumentos no responden a situaciones actuales del mercado si los precios, por alguna razón, han caído. Al mismo tiempo, el uso de una fórmula siempre estará acompañada de críticas, sin importar lo precisa que esta sea para reflejar los reales precios, debido a la incapacidad del público en general para entender cómo cada uno de sus componentes son afectados cuando cambian las condiciones del mercado. 
Tomemos el caso de algún producto importado, como alimentos, electrodomésticos u otro producto de importancia para la vida cotidiana. Los ciudadanos nunca relacionan los aumentos de precios de estos productos con decisiones del Gobierno. Los ciudadanos tampoco salen a la calle a realizar protestas ni tampoco son realizadas manifestaciones de paros de grupos sindicales cuando los precios de estos productos aumentan. Esto se debe a que la ciudadanía, aunque exprese su descontento de diversas formas, entiende que el Gobierno no es el último responsable de las variaciones de precios. Este es un fenómeno que no solo ocurre con los combustibles, sino también con cualquier otro producto regulado, como es el caso de la energía eléctrica, el agua, entre otros. Igualmente, el Gobierno enfrenta un costo político cuando salen a dilucidarse en los medios casos de corrupción en el manejo de los subsidios o en la asignación de cuotas establecidas al sector transporte, sin importar que estos casos sean infundados.

En ese sentido, entendemos que si el mercado de combustibles opera como cualquier otro mercado de productos esenciales importados, donde el Gobierno limita su rol a ser un ente regulador en el establecimiento de costos de calidad y temas de seguridad industrial, entonces el Gobierno no tendría la necesidad de asumir el costo político de las variaciones de precios que, en muchos casos, vienen determinadas por movimientos en los mercados internacionales que son inevitables.

\section{Conclusiones}

En las últimas décadas se ha observado cómo la mayoría de los países desarrollados sustentan el progreso y el crecimiento económico en la libertad de los mercados, es decir, entre la libre dinámica de oferta y demanda. La economía de mercado es la que crea y garantiza las condiciones necesarias para que la economía funcione. Esto se debe principalmente a que en medio del apogeo entre los distintos entes económicos - tanto del lado de la oferta como del de la demanda- por la supervivencia y la obtención de beneficios, la libre competencia crea los incentivos necesarios para que algunas empresas obtengan ventaja 
sobre otras, propiciando la reducción de los costos, aumentando la calidad de los productos y garantizando que los bienes y servicios que la gente prefiere sean ofertados. Esto no implica que el Estado no juegue un rol importante en ese desarrollo. Específicamente, el Estado debe proveer las condiciones necesarias para que sean respetados los derechos de propiedad, el cumplimiento de las leyes, la seguridad de la ciudadanía y se evite la creación de monopolios perjudiciales al consumidor y al mecanismo de competencia.

Se ha podido notar la gran importancia que tiene el mercado de combustibles en República Dominicana, conformando una gran parte de todas las importaciones del país. Pero, es un mercado con grandes trabas y restricciones de entrada, debido a la cantidad y el costo de los permisos requeridos para operar, siendo muchos de estos costos no fácilmente observables.

El mercado de importación en el país cuenta principalmente con REFIDOMSA, al importar la mayor proporción de petróleo y derivados del mercado, y un puñado de empresas privadas comparten el resto del mercado. El problema principal tocado en el presente ensayo ha sido con relación a la fórmula de Precios de Paridad de Importación (PPI). Esta se basa en el supuesto de que sirve para establecer un precio competitivo; sin embargo, está compuesta de variables y mecanismos que, de una u otra manera, crean ineficiencias en los precios y en el mercado. El uso de la fórmula establecida en la ley genera rigideces para establecer los precios, lo cual afecta la asignación eficiente de los recursos económicos y la toma de decisiones óptimas de inversión.

La fórmula del PPI presenta varios problemas que son abordados en este trabajo. Primero, el combustible utilizado como referencia Platt's no refleja el precio de importación de los combustibles dominicanos. Como mostramos mediante un análisis de regresión, el comportamiento del precio del combustible importado en el mercado dominicano es capturado de forma más precisa mediante un promedio ponderado del precio de los combustibles de referencia WTI y Brent. Segundo, la PPI emplea una serie de información con rezago (en algunos casos de hasta un año) de cotizaciones y facturas para definir costos operacionales actuales. Finalmente, dado el aumento 
en la eficiencia en las principales agencias recaudadoras, entendemos que los costos de cumplimiento, que son traspasados al consumidor, podrían reducirse si estos son concentrados en una sola agencia tributaria, como la DGII.

Finalmente, culminamos este trabajo haciendo una crítica sobre la regulación de los márgenes de intermediación. Fijar márgenes de intermediación para todo el mercado no es adecuado, ya que no es posible observar los costos de operación y los niveles de eficiencia de cada uno de los actores. También, la fijación de márgenes de intermediación podría ser una limitante para la inversión y la modernización de las empresas que operan en el sector y limita que el mecanismo de competencia reduzca los precios según participen mayores empresas en el mercado de combustibles.

Otro punto para destacar es que el Gobierno enfrenta un enorme costo político al regular el precio de los combustibles. El uso de una fórmula para el establecimiento de precios, que puede resultar compleja para el ciudadano común, resulta en críticas cuando la ciudadanía no entiende o asocia el movimiento de los precios locales con los cambios en el entorno internacional. Además, el Gobierno se expone a la realización de protestas debido a que se asume como último responsable en la asignación de precios y a las críticas por corrupción por el manejo de los programas de subsidios, a pesar de que estas no tengan fundamento.

República Dominicana depende de la importación de combustibles para su crecimiento y desarrollo. En ese sentido, para garantizar el abastecimiento y el establecimiento de precios que reduzcan los costos energéticos y de transporte, tanto de empresas locales como de consumidores, es necesario contar con un mercado dinámico y competitivo que se enfoque en proveer una mayor variedad de productos a mejores precios. El país cuenta con un número importante de actores tanto en la importación, como en el transporte y la venta al detalle de combustibles, por lo que no hay razón para suponer que este mercado pueda operar de forma eficiente y competitiva. Al reducir los costos de entrada y agilizar el tiempo de espera para permisos de operación, sería posible dinamizar más aún este mercado. 
Esto no significa que el Gobierno no tenga un rol importante en el sector si implementamos una liberalización. El Gobierno puede seguir jugando una tarea crucial estableciendo y supervisando el cumplimiento de las normas de seguridad industrial que amerita la industria y supervisando que los consumidores obtengan el producto con la calidad establecida y ofertada. Esto no va en desmedro de las recaudaciones impositivas que el Gobierno obtiene de este sector, que son de suma importancia para las finanzas públicas; el Gobierno podría tener incluso hasta una ganancia neta, ya que al limitar su participación reduce los costos que debe asumir como ente regulador. La regulación de precios es un mecanismo ineficiente de asignación de recursos y la historia ha demostrado que debe quedar en el pasado.

\section{Bibliografía}

[1] Hull, J. (2008a). Fundamentals of Futures and Options Markets. Hedging Strategies Using Futures. Pearson International Edition.

[2] Arezki R., Patillo C., Quintyn M \& Zhu M. (2012). "Commodity Price Volatility and Inclusive Growth in Low-Income Countries". Mexico's Oil Pirce_hedging Program, Javier Duclaud and Gerardo García International Monetary Fund.

[3] Banco Central de la República Dominicana. (2019). Sector Externo. Recuperado de Bancentral.gov.do: https://www. bancentral.gov.do/a/d/2532-sector-externo

[4] BP Statistical Review. (2013). BP Statistical Review of World Energy 2013. Londres: BP.

[5] Comisión Económica para América Latina y el Caribe. (2013). Centroamérica y República Dominicana: estadísticas de hidrocarburos, 2013. México: CEPAL.

[6] Comisión Económica para América Latina y el Caribe. (2017). Centroamérica: estadísticas de producción del subsector eléctrico, 2015. México: CEPAL.

[7] García, G. "Mexican Oil Income Stabilization Fund: Impact of the Financial crisis. November 2009”. Recuperado de https:// www.flar.net/documentos/2355_23-Gerardo_Garcia.pdf 
[8] Daniel, J. A. (2001). "Hedging Government Oil Price Risk", IMF Working Paper (WP/01/185).

[9] Dirección General de Impuestos Internos. (2019). Retrieved from Parque Vehicular: https://gii.gov.do/informacionTributaria/ estadisticas/parqueVehicular

[10] Ministerio de Industria, Comercio y Mipymes. (2019). Estadísticas Institucionales. Recuperado de micm.gov. do: https://www.micm.gob.do/direcciones/combustibles/ estadisticas-institucionales.

[11] Engel, E. \& Valdez, R. (2000). "Optimal Fiscal Strategy for Oil Exporting Countries”. IMF Working Paper 00/118.

[12] Yépez-García, R. \& Dana, J. (2012). Mitigación de la vulnerabilidad a los precios del petróleo altos y volátiles: experiencia del sector eléctrico en América Latina y el Caribe. Washington, DC: Banco Mundial

[13] Baconn, R. \& Kojima, M. (2006). Coping with Higher Oil Prices. Programa de Asistencia para la Gestión del Sector Energético (ESMAP) Informe 323/06. Washington: Banco Mundial.

[14] Bacon, R. \& Kojima, M. (2008). "Oil price risk: measuring the vulnerability of Oil Importers", Public Policy for the Private sector, Nota número 320. Washington: Banco Mundial.

[15] Banco Mundial. (2006). Assesing the Impact of Higher Oil Prices in Latin America. Economic Policy Sector. Washington: Banco Mundial.

[16] Lu, Y. \& Neftci, S. (2008). Financial Instruments to Hedge Commodity Price Risk for developing Countries. IMF Working paper (WP/08/6).

[17] Till, H. (2014). “An Update on Empirical Relationship in the Commodity Futures Markets" CME Group. Recuperado de http://www.cmegroup.com/trading/agricultural/files/anupdate-on-empirical-relationships-in-the-commodity-futuresmarkets.pdf

[18] Spatafora, N. \& Samake I. (2012). "Commodity Price Shocks and Fiscal Outcomes". IMF Working Paper (WP/12/112). 
[19] Trading WTI and Brent 101. CME Group as the exchange of choice. Asia Research Team- Recuperado de http://www. cmegroup.com/trading/energy/files/trading-wti-and-brent-101. pdf

[20] NYMEX. A guide to Energy Hedging. New York, NY: New York Mercantile Exchange. Recuperado de http://www.kisfutures. com/GuideEnergyHedging_NYMEX.pdf

[21] Somesatto, E. \& Satyanarayan, S. (1999). Trade Offs from Hedging Oil price Risk in Ecuador. Washington, D.C.: World Bank Group.

[22] Varangis, P. \& Larson, D. (1996). "Dealing with Commodity Price Uncertainity". Policy Research Working Paper. (WPS 1657) World Bank.

[23] Vásquez-Ruíz, H., \& Rivas, R. (2013). Análisis del TCR en República Dominicana: un Estudio en base a las metodologías de estimación del Fondo Monetario Internacional. Monetaria $36(1)$.

[24] Lindahl, M. (1996). A Hedging Strategy for Alaska: Learning from the Texas Experience. The Journal of Energy Finance and Development, 1(1): 9-20.

[25] Stulz, R. "Optimal Hedging Policies". Journal of Financial and quantitative analysis, 19(2), 127-40 


\begin{abstract}
Anexos
A. Impacto de los combustibles en la balanza de pagos

A pesar de que el objetivo de este trabajo no es cuantificar el impacto de las fluctuaciones de los combustibles en la balanza de pagos, decidimos emplear un análisis de regresión con el fin de determinar la importancia de realizar estrategias de coberturas de precios para aminorar el impacto negativo que tienen las fluctuaciones de los combustibles en la economía dominicana.

La tabla A.1 muestra los resultados de un modelo de regresión que relaciona el cociente del resultado de la cuenta corriente de la balanza de pagos sobre el PIB y sus variables determinantes. Las estimaciones fueron realizadas con datos trimestrales de la economía dominicana para el período 2000Q3- 2015Q4.
\end{abstract}


Y. BeNZAN, O. BRITO,

TABla A.1. Efecto Del PReCio del Petróleo en la CUenta CoRriente DE LA BALANZA DE PAGOS DOMINICANA

\begin{tabular}{|c|c|c|c|c|}
\hline $\begin{array}{l}\text { Variable dependi- } \\
\text { ente } \mathrm{CC}_{t} / \mathrm{PIB}_{t}\end{array}$ & Estimación 1 & Estimación 2 & Estimación 3 & Estimación 4 \\
\hline \multirow[t]{2}{*}{$\begin{array}{l}\text { Log(Precio } \\
\text { Petróleo) }\end{array}$} & -0.137230 & -0.124467 & -0.089362 & $-0.128705 * *$ \\
\hline & $(0.0000)$ & $(0.0000)$ & (0.0119) & $(0.0161)$ \\
\hline \multirow[t]{2}{*}{$\log (\mathrm{TCR})$} & & 0.336220 & 0.327882 & 0.052325 \\
\hline & & $(0.0008)$ & $(0.0015)$ & $(0.6242)$ \\
\hline \multirow[t]{2}{*}{$\begin{array}{l}\log (\text { Consumo } \\
\text { Final })\end{array}$} & & -0.026300 & -0.023653 & $-0.778060^{* *}$ \\
\hline & & $(0.2133)$ & $(0.2803)$ & $(0.0192)$ \\
\hline \multirow{2}{*}{$\begin{array}{l}\log (\text { Apertura } \\
\text { Comercial) }\end{array}$} & & & 0.206871 & 0.273170 \\
\hline & & & $(0.1792)$ & $(0.1731)$ \\
\hline \multirow[t]{2}{*}{$\mathrm{CC} / \mathrm{PIBt}-2$} & & & 0.036357 & $-0.210217 * * *$ \\
\hline & & & $(0.7733)$ & $(0.0941)$ \\
\hline \multirow{2}{*}{$\begin{array}{l}\log (\text { Formación } \\
\text { Bruta Capital })\end{array}$} & & & & $-0.296475 * *$ \\
\hline & & & & $(0.0277)$ \\
\hline \multirow[t]{2}{*}{$\log$ (PIB percap) } & & & & $1.092601 * * *$ \\
\hline & & & & $(0.0037)$ \\
\hline \multirow{3}{*}{$\begin{array}{l}100 * \text { Población } \\
>60 \text { años }\end{array}$} & & & & $0.198971 *$ \\
\hline & & & & \\
\hline & & & & $(0.1017)$ \\
\hline \multirow[t]{2}{*}{$\mathrm{d} 2008 \mathrm{q} 2$} & & & & -0.119585 \\
\hline & & & & $(0.1133)$ \\
\hline Constante & 0.480 & -0.200 & -0.310 & $15.229 * * *$ \\
\hline$R 2$ & 0.412 & 0.540 & 0.583 & 0.751 \\
\hline$N$ & 57 & 57 & 55 & 54 \\
\hline F-Stat & 38.599 & 20.760 & 13.713 & 14.754 \\
\hline
\end{tabular}

Notas: *** Significativo al 1\%, ** al 5\%, * al 10\%. Residuos pasan pruebas de normalidad y de no autocorrelación serial. El precio del petróleo fue calculado tomando como referencia el promedio simple de los barriles de referencia WTI, Brent y Dubbai. 
El coeficiente de la variable del precio del petróleo es significativo y tiene el signo adecuado. La estimación sugiere que el aumento de un $1 \%$ en el precio del petróleo incremente el déficit de la balanza de pagos, como proporción del PIB, en un $0.128 \%$. La magnitud del incremento del déficit es altamente significativa, ya que esto equivale a un aumento de casi US\$80 millones de dólares en el déficit de la balanza de pagos, si consideramos el PIB nominal estimado para el año 2014.

La tabla A.2 presenta la estimación del déficit de cuenta corriente de equilibrio estimado para la República Dominicana, según la metodología desarrollada en Ca'Zorzi \& Dieppe (2012). Para esta estimación utilizamos un panel de datos desbalanceado para un grupo de 163 países, que cubren el período anual comprendido entre 19682011. La variable "Exportador Neto de Petróleo" es una variable dicotómica que toma el valor de 1 , si el país en cuestión es exportador neto, y cero en caso contrario. 
Tabla A.2. Estimación de la cuenta CORRIEnTE DE EQUILIBRIO DOMINICANA

\begin{tabular}{|c|c|c|c|}
\hline Variable dependiente: $\mathrm{CC}_{t} / \mathrm{PIB}_{\mathrm{t}}$ & Pooled 1 & Pooled 2 & $\begin{array}{c}\text { Efectos } \\
\text { Fijos }\end{array}$ \\
\hline Activos internacionales netos & $0.025 * * *$ & $0.024 * * *$ & $0.012 * * *$ \\
\hline Inversión & $-0.034 * * *$ & $-0.032 * * *$ & $-0.031 * * *$ \\
\hline Crecimiento del PIB real & -0.001 & -0.001 & -0.033 \\
\hline Ingreso relativo & $0.422 * * *$ & $0.521 * * *$ & $0.522 * *$ \\
\hline$(\text { Ingreso relativo })^{2}$ & $-0.365 * * *$ & $-0.480 * * *$ & -0.536 \\
\hline Integración comercial & $0.008^{* * *}$ & $0.009 * * *$ & $0.019 * * *$ \\
\hline Integración financiera & $-0.020 * * *$ & $-0.025^{* * *}$ & $-0.032 * * *$ \\
\hline Cambio en el precio del petróleo & -0.009 & $0.011 * * *$ & $0.008 * *$ \\
\hline \multicolumn{4}{|l|}{ Controles: } \\
\hline Exportador neto de petróleo & $\mathrm{Si}$ & No & No \\
\hline Demográficos & $\mathrm{Si}$ & $\mathrm{Si}$ & $\mathrm{Si}$ \\
\hline$R^{2}$-Ajustado & 0.149 & 0.102 & 0.468 \\
\hline Error estándar del modelo & 8.321 & 8.52 & 6.583 \\
\hline $\mathrm{CC}_{t} / \mathrm{PIB}_{\mathrm{t}}$ Estimada para RD & $-5.27 \%$ & $-3.92 \%$ & $-3.36 \%$ \\
\hline
\end{tabular}

Notas: $* * *$ Significativo al $1 \%, * *$ al $5 \%, *$ al $10 \%$.

Fuente: Vásquez, Mota, Rivas \& Díaz (2012).

La última línea de la tabla presenta el cálculo del déficit de cuenta corriente de equilibrio para la República Dominicana, el cual se define como el ratio de Cuenta Corriente sobre PIB que está acorde a los fundamentos económicos de la nación.

La estimación sugiere que el costo que enfrenta República Dominicana por ser un país importador neto de petróleo, en términos de su cuenta corriente, está en torno a un $1.35 \%$ y un $1.96 \%$ del PIB. Es decir, si República Dominicana fuese exportadora neta de combustibles, la economía podría soportar un déficit de cuenta corriente sobre PIB de hasta un 5.27\%; sin embargo, debido a que 
República Dominicana es importadora neta de combustibles, el déficit de cuenta corriente que está acorde con la capacidad de la economía está entre un $3.92 \%$ y un $3.36 \%$ del PIB. 